\title{
Work design and its Relationship to Nurses Involvement in Decision Making and their Productivity Heba A. Ali ${ }^{1}$, Sanaa M. Safan ${ }^{2}$ and Sohair M.Mabrouk ${ }^{3}$ \\ ${ }^{1}$ B.Sc. Nursing Science, ${ }^{2}$ Assistant Professor of Nursing Administration, ${ }^{3}$ Assistant Professor of Nursing Administration, Faculty of Nursing, Menoufia University ${ }^{23}$
}

\begin{abstract}
Work design includes characteristics of the job and the nature of the work which have an important role in helping to reach the highest level of staff nurses' performance and promote productivity through involving nurses' decision making process. The purpose of this study was to investigate work design and its relationship to nurses' involvement in decision making and their productivity. Design: a descriptive corelational research design. A convenient sample of 400 staff nurses was selected to carry out this study. Setting; this study was conducted at Menoufia University Hospital at Shebin El-Kom, Menoufia Governorate/Egypt. Three Instruments were used. Work design questionnaire, Decisional making scale and Productivity questionnaire tool. Results: there was a positive statistically significant correlation between studied staff nurses' work design, decision making involvement, and productivity. The majority of studied staff nurses had moderate levels of work design characters; the first ranking with the highest mean score was social characteristics while the last ranking was task character. In addition, the majority of studied staff nurses had low levels of decisionmaking involvement, and less than one five of them had moderate and high level of decision-making involvement; the first ranking was related to collaboration liaison activities while the last ranking was related to professional recruitment. Moreover, more than two third of studied staff nurses had low levels of productivity, nearly one fifth of them had moderate level of productivity. Otherwise, the minority of them had high levels productivity. Additionally, the first ranking of productivity was work organization and the last ranking with the lowest mean score of productivity was working conditions. Conclusion: there was positive highly statistically significant correlation between work design and both decisions making involvement and their productivity. Recommendation; continuing education programs and training courses for nurse manager and their staff about work design character, decision making involvement that can be used to increase staff nurses productivity.
\end{abstract}

Key words: Work design, nurses' involvement, decision making, and productivity.

\section{Introduction:}

Work design takes on special importance in today's human resource management as it considered as an effective tool to meet the needs of the nurses and satisfy the interests of the hospital. There are three main work design techniques are job rotation, job enlargement, and job enrichment (Bullock, Alapaty, Herwehe, \& Kain, 2015). Job rotation enables the development of the nurses' skills, their hospital retention, reduces job boredom, while at the same time it reduces the exposure of nurses to work-related injuries. Job enlargement adds more tasks to the existing tasks of the nurse, thus increasing nurse Participation in the decision-making process. Job enrichment makes work more challenging and interesting and also enables the participation of nurses in the decision-making process, and to increase their work satisfaction that leading to high levels of performance and productivity. (Oshodi, Bruneau, Crockett, Kinchington, Nayar, \& West, 2019). 


\section{Work design and its Relationship to Nurses Involvement in Decision Making and their Productivity}

Work design plays an important role to reach the highest level of nurse's performance, motivation, satisfaction and prevent role ambiguity of the work. The presence and using work design in any organization help in improving nurse's involvement in decision making and making shared governance as a result from a variety of managerial decisions that affect directly and indirectly on hospital productivity (Van Bogaert et al.,

2014). The clarity of work design has a significant autonomy in making decisions, gives a chance to use judgment in carrying out the work and involving subordinates in decision making process in the organization are mainly for productivity and morale. (Arif, Zahid, Kashif, \& Sindhu, 2017).

Decision making mean an art considering and making a judgment concerning a particular issue or issues, it is an essential component of professional nursing care, nurses' ability to make effective decisions is the most important factor affecting the quality of care (Jeffreys, 2015). Nurses make two types of decisions related to practice: patient care decisions that affect direct patient care, and condition- of work decisions that affect the work environment or groups of patients. The dynamic and uncertain nature of health care environment requires nurses to be competent decision makers in order to respond to clients' needs (Zafarnia, Abbaszadeh, Borhani, Ebadi, \& Nakhaee, 2017).

Leadership occurs at all levels within an organization. It is the process of supporting others to improve client care and services by promoting professional practice (Cho, Lee, Kim, Kim, Lee, Park, \& Sung, 2016). Effective leadership is demonstrated by staff participation in decision making, the philosophy of the organization and the style of individual leaders within the organization, Leadership competencies of influencing staff and stimulating growth and development of staff are believed to be more important to increase staff participation in decision making. Influencing staff by developing a trust relationship between nurse managers and their staff encourages staff to talk about their ideas and concerns (Breaugh , Ritz \& Alfes, 2018) .

One important aspect of the professional role of nurses is the belief in autonomous nursing practice that can be expressed as greater involvement in clinical decision making, nurses also should educate to be socialized to value autonomy, use problem solving skills, critical thinking and reflection to develop good clinical decision-making abilities and in turn, expect a high level of involvement in clinical decision-making. However, despite nurses being equipped with the necessary skills to make decisions regarding patient care, they still feel their participation in clinical decision-making is being constrained (Melin, 2017).

Productivity is a universal concept that applies to all systems in hospitals because every activity requires productivity in its implementation. Productivity is a measurement of how a productive process produces an output; productivity is also defined as a ratio between input and output, with a focus on the output produced by a process. Nurses productivity can be assessed from what the individual does in his work, in other words, the nurses productivity is how a person performs his work or performance. A 


\section{Work design and its Relationship to Nurses Involvement in Decision Making and their Productivity}

productive person will describe the potential, perception, and creativity that always contribute to his ability to benefit himself and his organization. Quality of working life is an essential issue in health organizations (Hee \& Kamaludin (2016).

Moreover, productivity arises when nurses' ideas are stimulated involving them in greater participation on decision-making. To maximize productivity, management must value and nurture its most important assets, namely, nurses (workers) towards higher levels of competency, efficiency, creativity and fulfillment are encouraged and supported because nurses are the central resource in any healthcare setting. (Park \& Kim 2017).

\section{Purpose}

The purpose of this study is to investigate work design and its relationship to nurses' involvement in decision making and their productivity.

The following research questions were developed to conduct this study:

- What is the actual characteristics work design?

- What are the levels of staff nurses involved in decision making?

- What are the levels of nursing productivity?

- Is there a relation between work design, decision making and productivity among studied staff nurses?

\section{Methods}

1. Research Design: A descriptive correlational research design was used to achieve this purpose of the study.

2. Research Setting: This study was conducted in different units and departments at the units of Menoufia University hospitals.They were divided into two categories: Critical care units which include Emergency, Operative rooms, Adult ICU, Pediatric ICU, and Hemodialysis Unit. Inpatient units include the following units: Medical, Surgical, Obstetrics and Gynecology, Orthopedics and Oncology departments.

3. Sample: A convenient sample size was calculated utilizing $G$ Power program, with a power of 0.95 , alpha of 0.01 , and a medium effect size. The total number of staff nurse was 1200, the minimum sample size required for Pearson correlation analysis was 367 respondents. Sample size was determined by using solving formula to assess the sample size of staff nurses; $\mathrm{n}=\mathrm{N} \backslash 1+(\mathrm{N}$ e 2$)$ .Where $(\mathrm{n})=$ sample size, $(\mathrm{N})=$ is the total number of staff's nurse (1200). (e) = error tolerance (.05), $1=$ a constant value. Sample size of staff nurse $=1200 \backslash(1200 \mathrm{x}$ (.05) 2$)=400$.

4. Instruments: three instruments were utilized for data collection:

\section{Instrument I:}

Work design questionnaire. It consists of two parts. Part I: Demographic characteristics such as age, sex, educational level, work units and departments, years of experiences, and distance from home to work. Part II Work design questionnaire tool was adopted from Frederick (2015) and modified by the investigator. It was used to determine the characteristics and the nature of the work to nurse during performance at their work setting. It consists of four dimensions: task characteristics 12 items such as my job allow me to make my own decisions about how to 


\section{Work design and its Relationship to Nurses Involvement in Decision Making and their Productivity}

schedule my work...etc, knowledge characteristics 8 items such as my job requires that I only do one task or activity at a time...etc, social characteristics 10 items such as I have the opportunity to develop close professional friendships in my job...etc and work context 9 items such as the seating arrangements on the job are adequate (e $\mathrm{g}$, ample opportunities to sit, comfortable chairs) ...etc.

\section{Scoring system of instrument one:}

\begin{tabular}{|l|l|}
\hline Disagree & 1 \\
\hline Uncertain & 2 \\
\hline Agree & 3 \\
\hline
\end{tabular}

Three - Point's Likert scale type will be used for each statement in the second part as follows:

The scores of the items were summed up and total divided by the number of the items, giving a mean score for the part. These scores were converted into a percent score. The domain was considered to be a high score indicate a high level of nurse's work design character, if the percent score was equal $75 \%$ and more, if the percent score was $60 \%$ to $74 \%$, they indicate moderate level that nurses had work design character and lower level indicates nurses had work design character if low or less than $60 \%$ (Binea, 2013).

\section{Instrument II:}

Staff nurses' participation in decision making questionnaire. This instrument was used to measure actual decision involvement for nurses. It was adopted from Said (2014). It consisted of 22 items. Unit staffing contained 2 items (e.g. scheduling ...etc.,) Quality of professional practice included 5 items (e.g. development of practice standards ...etc.,) professional recruitment was 4 items (e.g. recruitment of RNs to practice on the unit...etc.,) .Using governance and leadership was 4 items (e.g. recommendation of disciplinary action for RNs...etc.,). Quality of support staff practice contained 4 items (e.g. development of standards for RN supports staff...etc.) Collaboration - liaison activities included 3 items (e.g. Liaison with other departments related to patient care...etc.).

\section{Scoring system of instrument two:}

The responses were scored on a five Point's Likert scale rating from (1 to 5) as following:

\begin{tabular}{|l|l|}
\hline Administration -management only & 1 \\
\hline $\begin{array}{l}\text { Primarily administration +management with some } \\
\text { nurse input }\end{array}$ & 2 \\
\hline $\begin{array}{l}\text { Equally shared by administration =management } \\
\text { and staff nurses }\end{array}$ & 3 \\
\hline $\begin{array}{l}\text { Primarily staff nurses with some administration } \\
\text { +management input }\end{array}$ & 4 \\
\hline Staff nurses only & 5 \\
\hline
\end{tabular}

The scores of the items were summed -up and total divided by the number of the items, giving a mean score for the part. These scores were converted into a percent score.

\section{Total scoring system}

\begin{tabular}{|l|l|}
\hline High Involvement & $\geq 75 \%$ \\
\hline Moderate involvement & $60 \%$ to $\leq 75 \%$ \\
\hline Low involvement & $\leq 60 \%$ \\
\hline
\end{tabular}

\section{Instrument (III): Productivity} questionnaire tool:

It used to determine the level of productivity elicited by nurses. The responses were "Yes" or" No". It grouped under eighteen dimensions as get the aim 6 items, working conditions 3 items, work engagement 5 items, work motivation 6 items, 


\section{Work design and its Relationship to Nurses Involvement in Decision Making and their Productivity}

work organization 2 items, Equipment and supplies 5 items, quality of nursing services 7 items, Employee growth (nurses) 4 items, problem solving and decision making 4 items.

Social relation 4 items, sick leave 5 items, work effectiveness 3 items, development and advancement 3 items, physical work environment 6 items, waste disposal 4 items, initiative 3 items, new skills 3 items and work habits 3 items.

\section{Scoring system of instrument three:}

Productivity questionnaire instrument: the questionnaire is (Yes) or (No) question. Each question was assigned a score of (1) if the answer Yes and (0) if the answer No (Abd Allah, 2011). A high level of productivity is considered if the total score ranges from $75 \%$ to $100 \%$. A moderate level of productivity is considered if the total scores ranges from $60 \%$ to 74 . If the total level was less than $60 \%$ this indicates low level of productivity.

Validity: Five experts were selected to test the content and face validity of the instruments. The panel included five experts from Nursing Administration department (3 professors and 2 assistant professors) at Faculty of Nursing Menoufia and Tanta University. No necessary modifications were required.

\section{Pilot study:}

It was carried out on $10 \%$ of the total sample 40 nurses after the instruments were developed and before starting the data collection to ascertain the clarity, relevance, applicability of the study instruments and to determine the obstacles that may be encountered during data collection. Pilot study sample was included in the studied sample.

Ethical Considerations: Approval of the Faculty of Nursing Ethical Research Committee was obtained before conducting the study. A written from consent was obtained from the sample after explaining the purpose, nature, time of conducting the study, potential benefits of the study and how data were collected. The respondents were assured that the data will be treated as strictly confidential; furthermore, the respondents' anonymity was maintained as they weren't required to mention their names.

\section{Procedure:}

1. An official permission to carry out the study was obtained from the directors of Menoufia University Hospital after submitting an official letter from the Dean of nursing Faculty.

2. Data was collected over three months started from 8th of December 2019 to the end of January, 2020 after securing necessary permission.

3. Before beginning to collect data from the study subjects the investigator introduced her to them, explained the purpose of the study, and informed them that their information would be treated confidentially and will be used only for the purpose of the research. Additionally, each participant was notified about the right to accept or refuse to participate in the study.

\section{Data Analysis}

The collected data were organized, tabulated, and statistically analyzed using SPSS version 20 created on IBM compatible computer. For numerical values the mean and 


\section{Work design and its Relationship to Nurses Involvement in Decision Making and their Productivity}

standard deviations were calculated. Chi square test was used to detect the statistical differences between variables. $T$ test was used to compare between two means of parametric data. Person correlation test was done to study the correlation between one qualitative variable and one quantitative variable or two quantitative variables of not normally distributed data the statistical difference was considered significant if $\mathrm{P}<0.05$.

\section{Results:}

Table1: Shows distribution of studied staff nurses regarding their socio demographic characteristics. As shown from this table the highest percent of nurses $(54.5 \%)$ and were females had $<30$ years old, also the highest percentage of the studied staff nurse had diploma $(56 \%)$. Regarding, Work units and department, the highest percentage of staff nurses had work at Critical care units $(71 \%)$.

Regarding years of experience, the highest per cent of studied staff nurses $(35 \%)$ was had $1-<5$ years of experience degree in nursing. Additionally, about third of them had suitable distance from their work.

Table 2 and Figure 1: Illustrate ranking with mean score of work design characters as reported by studied staff nurses. As notices from the table, the totals mean score of work design was $(84.28 \pm 12.54)$. Additionally, it showed that the first ranking with the highest mean score was $(24.55 \pm 3.86)$ related to social characteristics while the last ranking with the lowest mean score was $(20.33 \pm 3.8)$ related to task character.

Table 3 and figure 2: Illustrate ranking with mean score of total decision-making involvement as indicated by studied staff nurses. As notices from the table, the totals mean score of decision-making involvement was $(52.07 \pm 23.5)$ Additionally, it showed that the first ranking $(8.02 \pm 3.72)$ related to collaboration liaison activities while the last ranking was $(8.42 \pm 5.65)$ related to professional recruitment.

Table 4 and Figure 3: Displays ranking with mean score regarding total productivity as suggested by studied staff nurses. As notices from the table, the totals mean score related productivity was $(42.9 \pm 9.38)$. Additionally, it showed that the first ranking was $(1.67 \pm 0.69)$ related to work organization. While the last ranking with the lowest mean score was related to working conditions $(1.18 \pm 0.85)$.

Table 5, Figure 4 and Figure 5: Shows correlation between work design, decision making involvement and productivity among studied staff nurses. As noticed from the table, there was a very highly statistically significant positive correlation between work design and both decisions making involvement and product.

Table (1): Distribution of studied staff nurses according to their social characteristics $(n=400)$ : 


\begin{tabular}{|c|c|c|}
\hline Variables & No & \% \\
\hline \multicolumn{3}{|l|}{ Age } \\
\hline$<30$ years & 218 & 54.50 \\
\hline $30-40$ years & 156 & 39.00 \\
\hline$\geq 40$ years & 26 & 6.50 \\
\hline \multicolumn{3}{|l|}{ Sex } \\
\hline Male & 192 & 48 \\
\hline Female & 208 & 52 \\
\hline \multicolumn{3}{|l|}{ Educational qualification } \\
\hline - $\quad$ Nursing Bachelor & 72 & 19.00 \\
\hline Associated degree & 104 & 26.00 \\
\hline Nursing Diploma & 224 & 56.00 \\
\hline \multicolumn{3}{|l|}{ Work units and department } \\
\hline \multicolumn{3}{|l|}{ I- Critical care units: } \\
\hline - $\quad$ Emergency department & 30 & 7.50 \\
\hline Operating room $(\mathrm{OR})$ & 54 & 13.50 \\
\hline Adult Intensive Care unit & 76 & 19.00 \\
\hline Pediatric Intensive Care unit & 94 & 23.50 \\
\hline Hemodialysis Unit & 30 & 7.50 \\
\hline Total & 284 & 71.00 \\
\hline \multicolumn{3}{|l|}{ II-Inpatient department: } \\
\hline - $\quad$ Medical department & 62 & 15.50 \\
\hline Surgical department & 2 & 0.50 \\
\hline Obstetrics and Gynecology department & 20 & 5.00 \\
\hline Orthopedics department & 18 & 4.50 \\
\hline Oncology department. & 14 & 3.5 \\
\hline Total & 116 & 29.00 \\
\hline \multicolumn{3}{|l|}{ Years of experience } \\
\hline - $\quad<1$ year & 2 & 0.50 \\
\hline $1-<5$ & 140 & 35.00 \\
\hline $5-<10$ & 132 & 33.00 \\
\hline $10-<20$ & 100 & 25.00 \\
\hline - $\quad \geq 20$ & 26 & 6.50 \\
\hline \multicolumn{3}{|l|}{ The distance from your home to work } \\
\hline - $\quad$ Near & 92 & 23.00 \\
\hline Suitable & 226 & 56.50 \\
\hline Far & 82 & 20.50 \\
\hline
\end{tabular}

Table (2): Ranking with mean score of total work design character as reported by studied staff nurses ( $\mathrm{n}=$ 400):

\begin{tabular}{|l|c|c|c|c|c|}
\hline \multicolumn{1}{|c|}{ Work design items } & Minimum & Maximum & Mean \pm SD & Mean Percent \% & Ranking \\
\hline Task character & 12.00 & 34.00 & $20.33 \pm 3.81$ & 56.46 & 4 \\
\hline Knowledge characteristics & 8.00 & 24.00 & $18.94 \pm 3.94$ & 78.9 & 2 \\
\hline Social characteristics & 17.00 & 30.00 & $24.55 \pm 3.86$ & 81.82 & 1 \\
\hline Work context & 12.00 & 27.00 & $20.47 \pm 4.10$ & 75.82 & 3 \\
\hline Total work design & $\mathbf{5 5 . 0 0}$ & $\mathbf{1 1 0 . 0 0}$ & $\mathbf{8 4 . 2 8} \mathbf{\pm 1 2 . 5 4}$ & $\mathbf{8 4 . 2 8}$ & - \\
\hline
\end{tabular}

SD: Standard deviation 


\section{Work design and its Relationship to Nurses Involvement in Decision Making and their Productivity}

Figure (1): Ranking with Mean Score Regarding Work Design Characters as Reported by Studied Staff Nurses.

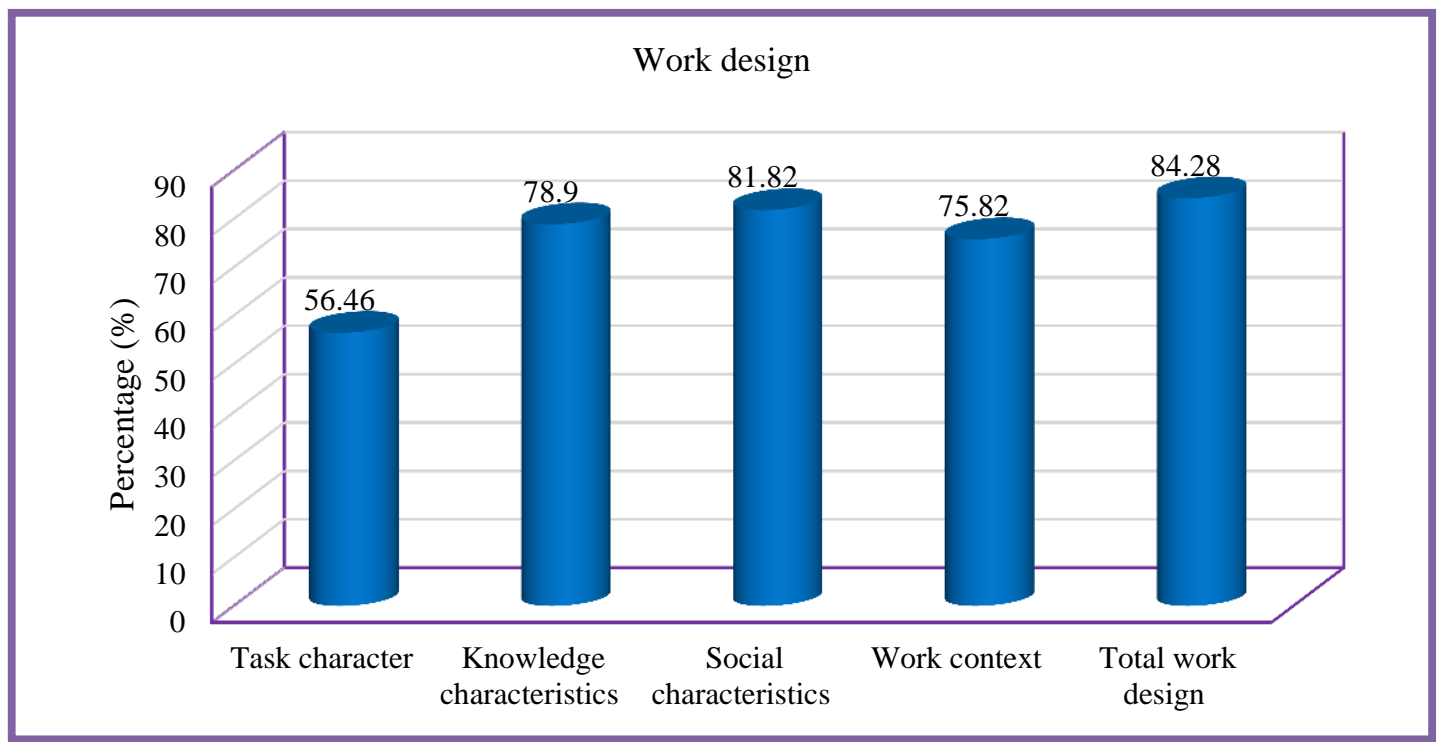

Table (3): Ranking with mean score of decision-making involvement as indicated by studied staff nurses $(n=400)$ :

\begin{tabular}{|l|c|c|c|c|c|}
\hline \multicolumn{1}{|c|}{ Decisional making involvement items } & Minimum & Maximum & Mean \pm SD & $\begin{array}{c}\text { Mean Percent } \\
\text { \% }\end{array}$ & Ranking \\
\hline Unit staffing & 2.00 & 10.00 & $5.32 \pm 2.82$ & 53.15 & 2 \\
\hline Quality of professional practice & 5.00 & 22.00 & $11.36 \pm 6.12$ & 45.46 & 4 \\
\hline Professional recruitment & 4.00 & 20.00 & $8.42 \pm 5.65$ & 42.1 & 6 \\
\hline Unit governance and leadership & 4.00 & 17.00 & $8.65 \pm 4.31$ & 43.25 & 5 \\
\hline Quality of support staff practice & 4.00 & 20.00 & $10.31 \pm 5.97$ & 51.53 & 3 \\
\hline Collaboration- liaison activities & 3.00 & 14.00 & $8.02 \pm 3.72$ & 53.43 & 1 \\
\hline Total decisional making involvement & $\mathbf{2 2}$ & $\mathbf{9 7}$ & $\mathbf{5 2 . 0 7 \pm 2 3 . 5}$ & $\mathbf{5 2 . 0 7}$ & - \\
\hline
\end{tabular}

SD: Standard deviation

Figure 2: Ranking with mean score regarding decision-making involvement as reported by studied staff nurses

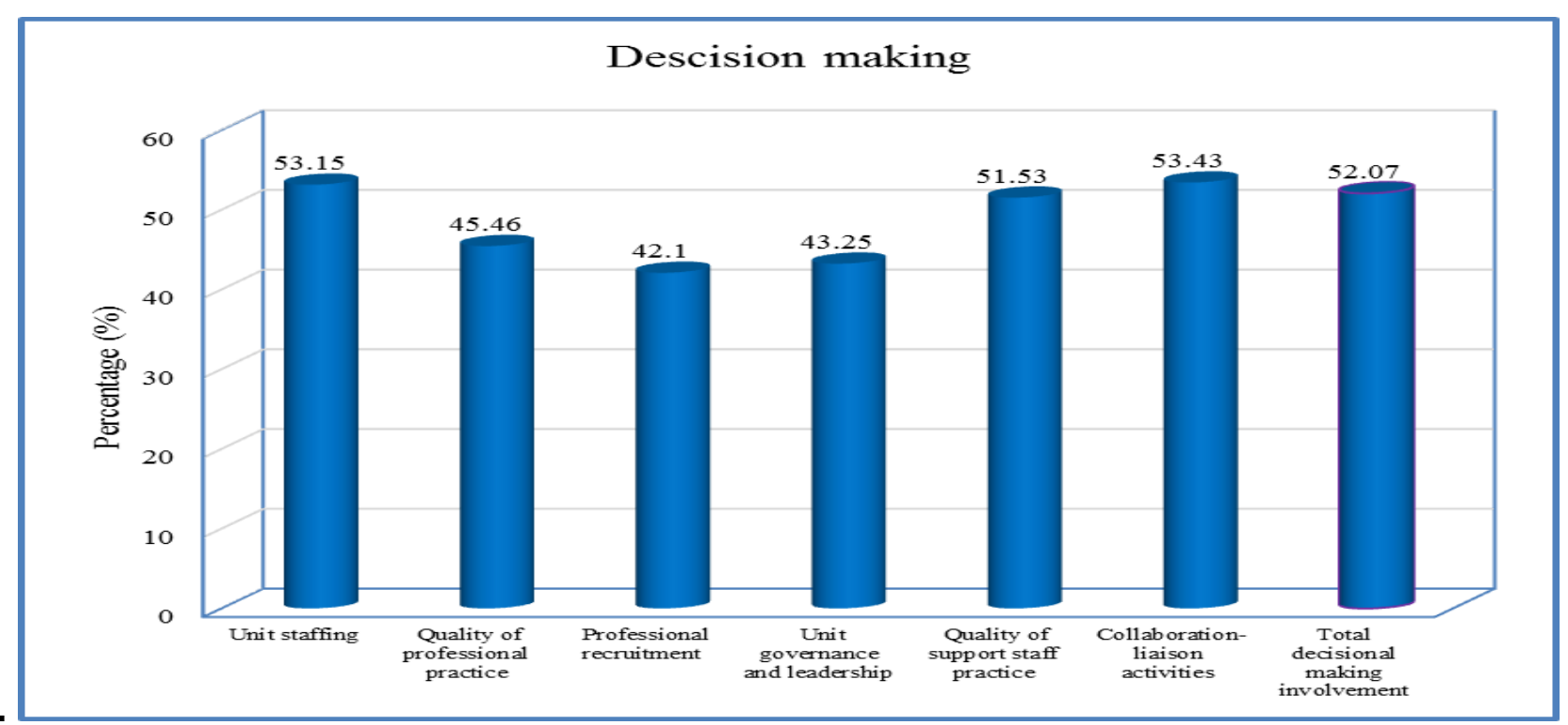




\section{Work design and its Relationship to Nurses Involvement in Decision Making and their Productivity}

Table (4): Ranking with mean score regarding productivity as reported by studied staff nurses ( $\mathrm{n}=$ 400):

\begin{tabular}{|l|c|c|c|c|c|}
\hline \multicolumn{1}{|c|}{ Productivity items } & Minimum & Maximum & Mean \pm SD & $\begin{array}{c}\text { Mean Percent } \\
\text { \% }\end{array}$ & Ranking \\
\hline Get the aim & 1.00 & 6.00 & $3.92 \pm 1.52$ & 65.33 & 6 \\
\hline Working conditions & 0.00 & 3.00 & $1.18 \pm 0.85$ & 39.33 & 18 \\
\hline Work engagement & 0.00 & 4.00 & $2.49 \pm 1.04$ & 49.9 & 12 \\
\hline Work motivation & 0.00 & 6.00 & $2.58 \pm 1.84$ & 43.08 & 17 \\
\hline Work organization & 0.00 & 2.00 & $1.67 \pm 0.69$ & 83.75 & 1 \\
\hline Equipment and supplies & 0.00 & 5.00 & $2.42 \pm 1.44$ & 48.3 & 13 \\
\hline Quality of services nursing & 0.00 & 7.00 & $3.55 \pm 2.34$ & 50.64 & 11 \\
\hline Employee growth (nurses) & 0.00 & 4.00 & $2.06 \pm 1.05$ & 51.63 & 10 \\
\hline Problem solving and decision making & 0.00 & 3.00 & $1.31 \pm 1.02$ & 43.67 & 15 \\
\hline Social relations & 0.00 & 4.00 & $2.60 \pm 1.61$ & 65.00 & 7 \\
\hline Sick leave & 0.00 & 5.00 & $2.87 \pm 1.65$ & 57.4 & 9 \\
\hline Work effectiveness & 0.00 & 3.00 & $1.97 \pm 1.03$ & 65.83 & 5 \\
\hline Development and advancement & 0.00 & 3.00 & $1.30 \pm 1.02$ & 43.33 & 16 \\
\hline Physical work environment & 1.00 & 6.00 & $3.82 \pm 1.75$ & 63.67 & 8 \\
\hline Waste disposal & 0.00 & 4.00 & $3.30 \pm 1.19$ & 82.5 & 2 \\
\hline Initiative & 0.00 & 3.00 & $1.42 \pm 1.13$ & 47.17 & 14 \\
\hline New skills & 0.00 & 3.00 & $2.19 \pm 0.89$ & 73.17 & 4 \\
\hline Work habits & 0.00 & 3.00 & $2.26 \pm 0.84$ & 75.33 & 3 \\
\hline \multicolumn{1}{|c|}{ Total productivity } & $\mathbf{2 4 . 0 0}$ & $\mathbf{6 5 . 0 0}$ & $\mathbf{4 2 . 9 \pm 9 . 3 8}$ & $\mathbf{4 2 . 9}$ & - \\
\hline
\end{tabular}

SD: Standard deviation

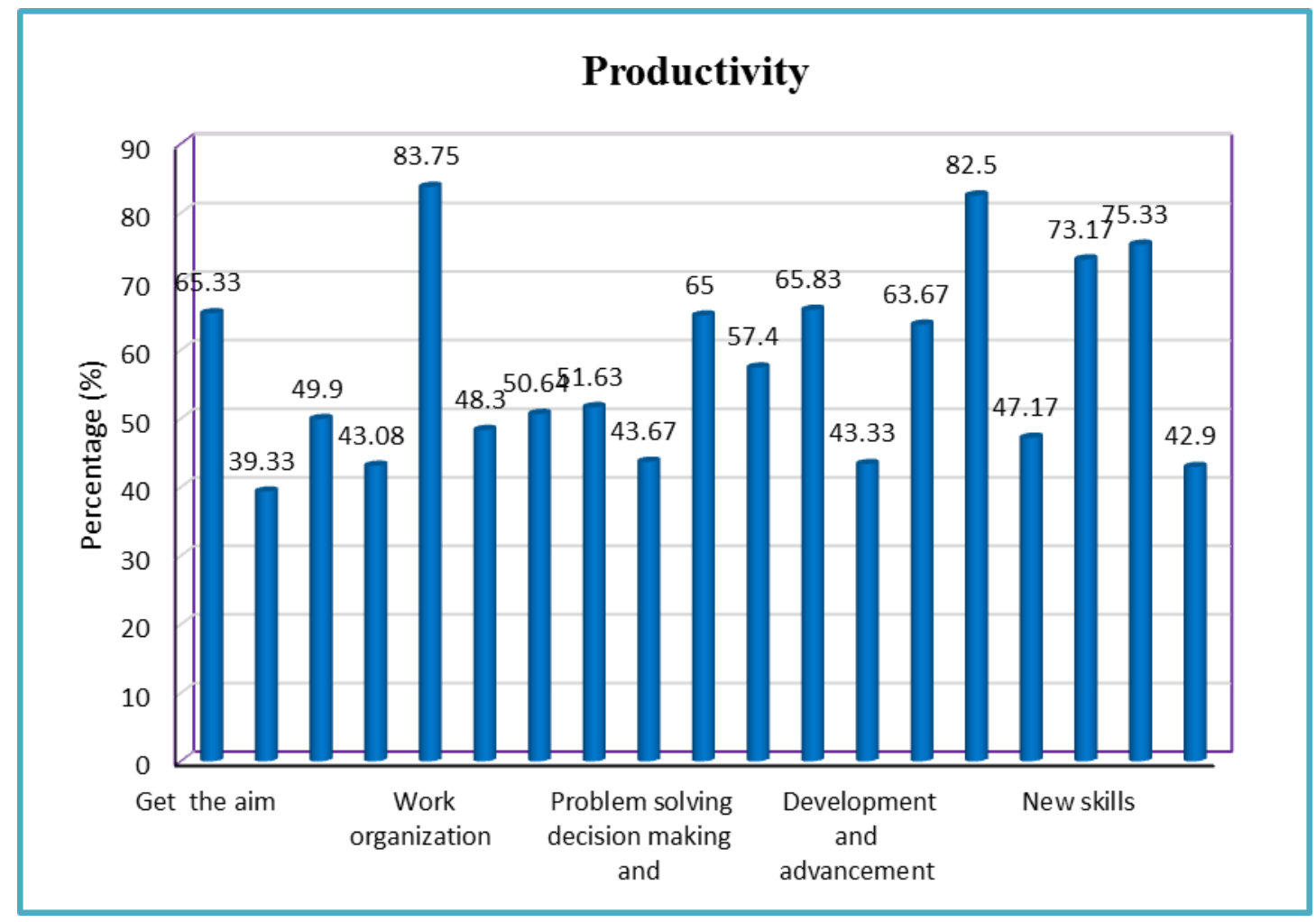


Work design and its Relationship to Nurses Involvement in Decision Making and their Productivity

Table (5): Correlation between work design, decision making involvement and productivity among studied subjects.

\begin{tabular}{|l|c|c|}
\hline \multirow{2}{*}{ Study variables } & \multicolumn{2}{|c|}{ Work design } \\
\cline { 2 - 3 } & r & p. values \\
\hline Decision making involvement & 0.368 & $0.000^{* *}$ \\
\hline Productivity & 0.345 & $0.000^{* *}$ \\
\hline
\end{tabular}

**=highly significant

Figure (4): Correlation between work design and decision making.

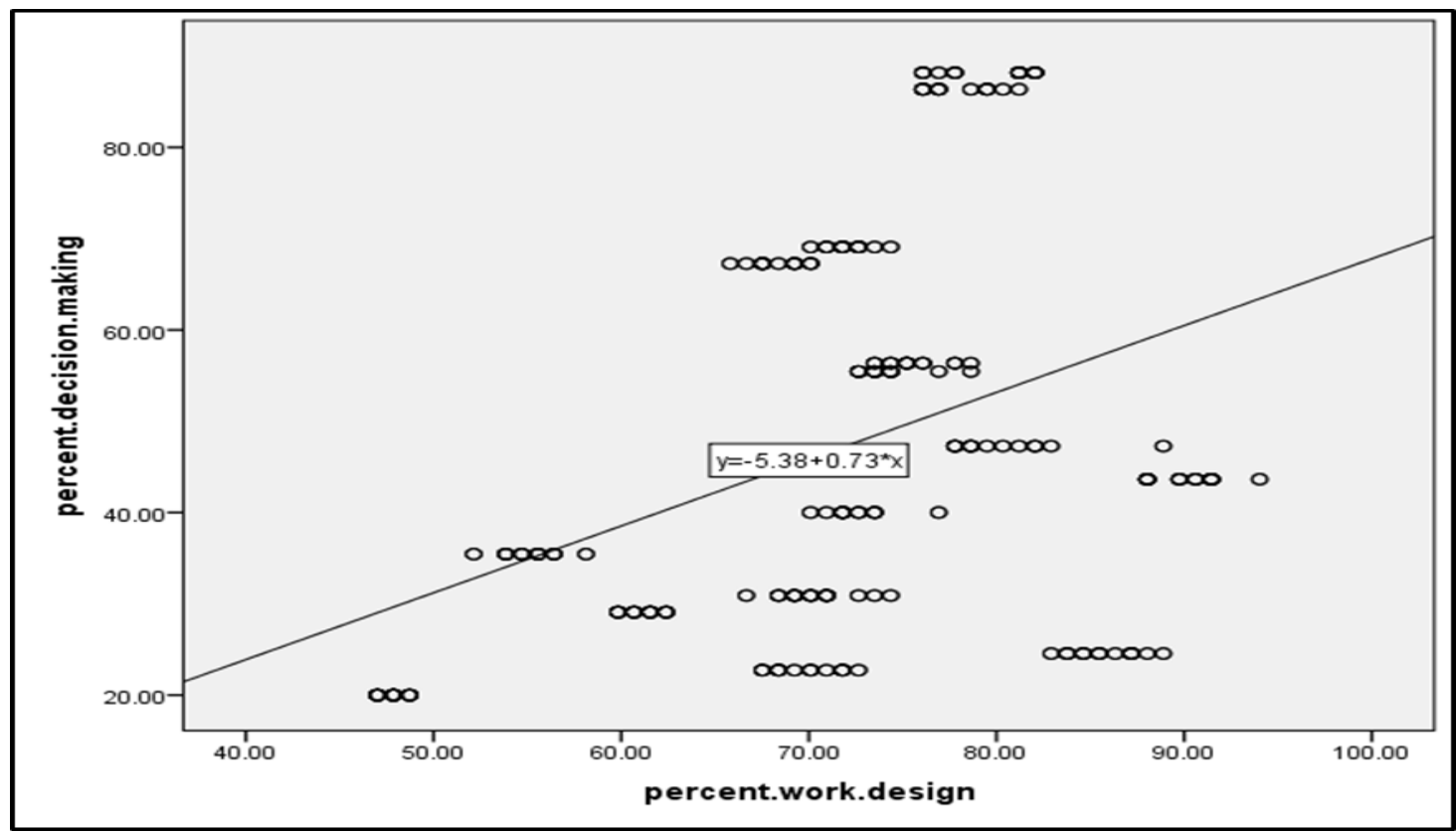

Figure (5): Correlation between work design and productivity.

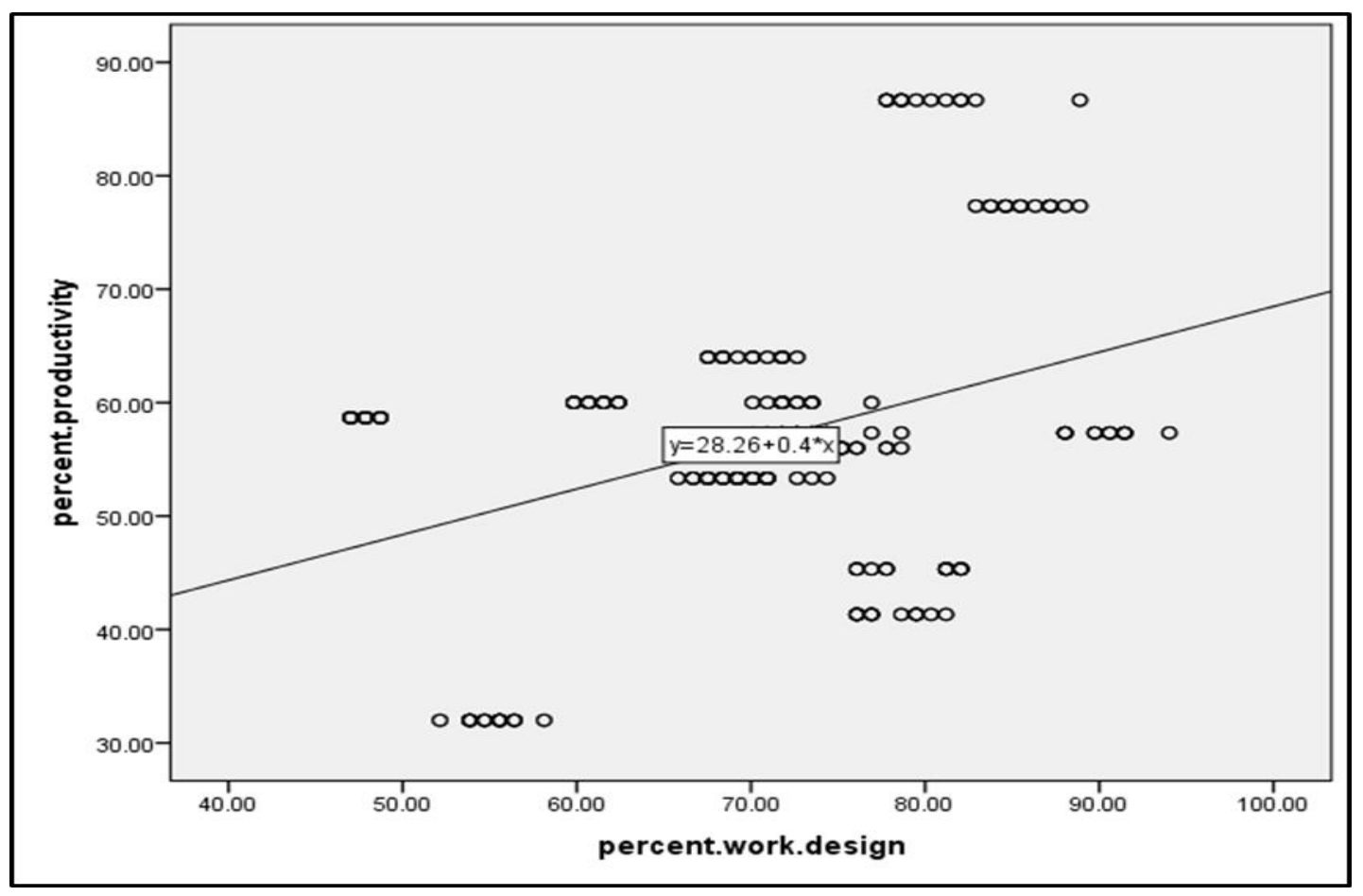




\section{Work design and its Relationship to Nurses Involvement in Decision Making and their Productivity}

\section{Discussion}

Work design plays an important role on satisfying the interests of both staff nurses and the hospital. Work design contributes to nurses' performance, efficiency, profitability and reduces nurses work tasks overlapping (Morgeson et al., 2019). Moreover, involving nurses' decisions in designated work environment.

direct patient care decisions and all nursing work related decisions are essential for the provision professional nursing care, enhancing nurses' motivation and engagement at the workplace , reducing nurses' problems, promoting job satisfaction, improving health organizations quality of working life, elevate creativity, promote effectiveness of nursing care and maximum nursing productivity (Loke, , Lee, Loh, \& Noor, ,2020).

Regarding work design items, the results of the present study showed that the most common predictors for work design were social characteristics while knowledge characteristics were the least predictor. From the investigator point of view this is might be due to social character constitutes the highest mean percentage due to the nature of nurses job requires to work closely with other, requires a lot of cooperative work with other people thus job depends on the work of many different people for its completion. This result was consistent with, Wöhrmann, Deller \& Wang (2013) who studied outcome expectations and work design characteristics in post-retirement work planning reported that, social characteristic in work design theory social support at work reflects the level of opportunities to receive assistance and advice, as well as to make friends at work.

This result inconsistent with Alcover \& Topa, (2018) who studied work characteristics,

motivational orientations, psychological work ability and job mobility intentions of older worker, and found that knowledge characteristics are the most relevant factors in perceptions of psychological work ability among older workers.

With reference to decision making involvement, the current study illustrated that first ranking was related to collaboration liaison activities while the last ranking was related to professional recruitment. From the investigator point of view, the collaboration liaison activities are important key to promote job cooperation, enhancing interdepartmental organizational communication within all levels because therefore services and activities dependent upon each other. While, the lowest mean score was professional recruitment among staff nurses because staff nurses hadn't any role in recruit nurses and it return to hospital needs and the administrative policy. These results agreed with ChisengantambuWinters, Robinson, \& Evans (2020) who studied developing a decision-making dependency (DMD) model for nurse managers, revealed that high quality, sound decision making is one of the major elements of good management and leadership in healthcare institutions.

With reference to productivity, the findings of our result revealed that the first ranking was related to work organization, from the investigator point of view, this is might be due to designated, organized, well equipped work environment help to be more productive and worked hours divided into shifts made a chance to work overtime for extra paid hours. While the last ranking was related to working conditions, from the investigator point of view, this is might be due to nursing shortage, and had not time to take rest.

This finding agreed with Aithal \& PM, (2016) who studied Optimizing Human Productivity. They demonstrated that, Optimizing Human Productivity (OHP) is a challenging process for the organization, and this process involves getting the best performance from employees within the organizational constraints. Optimizing Human Performance is used in all business functions to improve individual and 


\section{Work design and its Relationship to Nurses Involvement in Decision Making and their Productivity}

group output, reliability, and productivity. Employee growth and development towards higher levels of competency, creativity and fulfillment are encouraged and supported because people are the central resource in any organization. The most successful optimizing human productivity models have five key elements.

When implemented properly these elements enable organizations to thrive through the engagement of their employees. The important elements for OHP include Leadership Commitment, Human Capital Planning, Attracting, Developing, and Retaining Employees, Communications Strategy, and Impact Metrics. Optimization involves designing a system or process to perform as well as possible. Even though the performance of human resources in organizations mainly depends on the technology and external environment which substantially impacts organizational behavior, the way of thinking individually and by teams, and humanistic orientation, which assumes that individual feelings, attitudes, perceptions, goals, etc., are important to the organization.

Regarding correlations, the findings of our result revealed that there was a very highly statistically significant positive correlation between work design and both decisions making involvement and productivity. From the investigator point of view, this due to work design plays crucial part in supporting the staff' work performance in achieving organizational relevant outcomes especially when they involved in decision making as a motivational mediator, so it may directly or indirectly influences the manner, they perform their responsibilities and tasks.

Many researchers have tried to optimize productivity using different strategies, privatization of organizations, optimizing risks and optimizing rewards (Cascio \& Boudreau, 2018) etc. and its measurement. In addition, the study which was performed by Ali, Ali, \& Adan, (2013) who revealed that two variables of working condition and employee productivity in manufacturing companies in Mogadishu Somalia are positively correlated.
Regarding Relation between work design levels with decision making involvement, and productivity levels, this study showed that, there were statistically significant relationship was found between work design characteristics levels with decision making involvement, and productivity level $(\mathrm{p}<0.001)$.

Our results were in the same line with the study which was conducted by Yusof, Masrek, Noordin, \& Johare, (2012) who revealed that, the importance of job design in boosting individual's productivity and performance that job design plays crucial part in supporting the employees' work performance in achieving organizational relevant outcomes as it may directly or indirectly influences the manner, they perform their responsibilities and tasks. Hence, the job design characteristics need to be assessed and restructure constantly in order to maintain an efficient work performance and productivity.( Yusof, Masrek, Noordin, \& Johare, 2012) While, This findings disagreed with another study that conducted by Kapur, (2018)., on 111 participants to measure perceptions of student nurses about their own decision making. No statistically significant differences among juniors, and seniors were noted.

\section{Conclusion}

On the light of the current study, it can be concluded that Most of staff nurses had moderate level of nurse's work design character, low level of decision-making involvement and low level of productivity. Staff nurses' work design level character. Additionally, there was a highly significant positive relation with work design, decision making involvement and productivity.

\section{Recommendations}

In the light of the finding reached from the present study, the following points are recommended

\section{For hospital administrator:}

1-The managers should understand the importance of job design as an essential component of work behavior among the workforce. 


\section{Work design and its Relationship to Nurses Involvement in Decision Making and their Productivity}

2- Nurse Manager must optimize nurses' opportunities for personal and professional growth by creating a learning environment that enables reflective practice and shared accountability, demonstrate confidence in others by delegating effectively, coach, mentor, and guide and provide opportunities for the development of knowledge, skills.

3- The hospital administrators should provide nursing with resources that enable them to design the nursing work environment and care processes to reduce errors that affect their productivity

4- The nurse mangers must provide physically and psychologically supportive environment to nurses working that decrease the work problems, increase the level of decisionmaking involvement, and increase level of their productivity.

5- Nurse Managers must use interactive teaching strategies that improve skills of critical thinking and decision making for staff nurse.

6- Nurse Managers must conduct periodic meetings with nurses to discuss their needs and do everything in their power to meet these needs to create a motivated environment and increase their productivity.

7- Nursing director should increase involvement in decision making process and put an evaluative measure to be used as a standard in choosing managerial and administrative position regarding their abilities and skills regardless their ages for improving their productivity

\section{For education:}

1-Conducting continuing education programs and training courses for nurse manager and their staff about: work design character, decision making involvement that can be used to increase staff nurses productivity.

2- Decision making must be included in all nursing courses of nursing to enhance nurse's knowledge and practice about how to make effective decision.

\section{For further research:}

1-Reapplication of the study on the larger probability sample is highly recommended to achieve generalizable results.

2- Conduct study to investigate the factors that may affect nurse's involvement in decision making such as leadership strategies used by nurse mangers, also affected on staff nurses' work design and productivity.

3- Conduct study to identify strategies that increase work design characteristic level and its relation to nurses' productivity

\section{References}

bdAllah, R. (2011): The effect of models of organizing patient care on productivity at Shebin El Kom hospitals. Unpublished Master thesis, Faculty of Nursing, Menofia University. Egypt.

Aithal, S. \& PM K. (2016). Theory A for Optimizing Human Productivity. Published in: IRA-International Journal of Management \& Social Sciences.; (ISSN 2455-2267), Vol. 4, No. 3: pp. 526-535.

Aithal, S. \& PM K. (2016). Theory A for Optimizing Human Productivity. Published in: IRA-International Journal of Management \& Social Sciences.; (ISSN 2455-2267), Vol. 4, No. 3: pp. 526-535.

Alcover C \& Topa G. (2018). Work characteristics, motivational orientations, psychological work ability and job mobility intentions of older workers. PLoS One. Apr 27; 13(4):e0195973.

Ali A, Ali A, \& Adan A. (2013). Working conditions and employees' productivity in manufacturing companies in sub-Saharan African context: Case of Somalia. Educational Research International. Oct;2(2):67-78.

Arif M, Zahid S, Kashif U, \& Sindhu M. (2017). Role of leader-member exchange relationship in organizational change management: Mediating role of organizational culture. International Journal of organizational leadership. Oct $14 ; 6: 32-41$. 


\section{Work design and its Relationship to Nurses Involvement in Decision Making and their Productivity}

Binea J. (2013).Decisional involvement actual and preferred involvement in decision making among registered nurses. Western Journal of Nursing Research XXX.PP.116.

Bullock J, Alapaty K, Herwehe J, \& Kain J. (2015). Human resource management. A dynamically computed convective time scale for the Kain-Fritsch convective parameterization scheme. Monthly Weather Review. Jun; 143(6):2105-20.

Cascio, W., \& Boudreau, J. (2018). HR strategy: optimizing risks, optimizing rewards. Journal of Organizational Effectiveness: People and Performance.

Chisengantambu - Winters.C., Robinson, M., \& Evans, N. (2020). Developing a decision-making dependency (DMD) model for nurse managers. Heliyon, 6(1), e 03128 .

Cho E, Lee N, Kim E, Kim S, Lee K, Park K, \& Sung Y. (2016): Nurse staffing level and overtime associated with patient safety, quality of care, and care left undone in hospitals: a cross-sectional study. International journal of nursing studies. Aug 1; 60:263-71.

Frederick P. (2015): The Work Design Questionnaire (WDQ): developing and validating a comprehensive measure for assessing job design and the nature of work. Journal of applied psychology, 91(6), 1321.

Hee O. \& Kamaludin N. (2016): Motivation and Job Performance among Nurses in the Private Hospitals in Malaysia. International Journal of Caring Sciences. Jan $1 ; 9(1)$.

Kapur, R. (2018). Organization and Job Design. Motivation and Job Performance among Nurses in the Private Hospitals in Malaysia. International Journal of Caring Sciences. Jan 1; 9(1).

Loke, F., Lee, K., Loh, S., \& Noor, M. (2020). High fidelity full sized human patient simulation manikins: Effects on decision making skills of nursing students. Journal of nursing education and practice, 4(7).

Oshodi T, Bruneau B, Crockett R, Kinchington F, Nayar S, \& West E. (2019).Registered nurses' perceptions and experiences of autonomy: a descriptive phenomenological study. BMC nursing. Dec 1; 18(1):51.

Said,F. (2014): The effect of night shift among nurses on their involvement in decision making at Zagazig university hospitals'. Unpublished master thesis, Faculty of Nursing, Zagazig University. Egypt.

Salemm, A., (2018). The relationship between job design and nurses' satisfaction. SOJ Nur Health Care 4 (2): 1-9. The relationship between job design and nurses' satisfaction.

Van Bogaert P, Timmermans O, Weeks SM, van Heusden D, Wouters K, \& Franck E. (2014). Nursing unit teams matter: Impact of unit-level nurse practice environment, nurse work characteristics, and burnout on nurse reported job outcomes, and quality of care, and patient adverse events. A cross-sectional survey. International journal of nursing studies. 2014 Aug $1 ; 51(8): 1123-34$

Wöhrmann A, Deller J, \& Wang M. ( 2013). Outcome expectations and work design characteristics in post-retirement work planning. Journal of Vocational Behavior. Dec 1;83(3):219-28.

Yusof, I., Masrek, N., Noordin, A., \& Johare, R. (2012). Job design and knowledge productivity: A conceptual framework. In Proceeding of the 19th International Business Information Management (IBIMA) Conference (Vol. 12, p. 13th).

Zafarnia N, Abbaszadeh A, Borhani F, Ebadi A, \& Nakhaee N. (2017). Moral competency: meta-competence of nursing care. Electronic physician. Jun; 9(6):4553. 